\title{
Interannual salinification of the Mediterranean inflow
}

3 Claude Millot $^{1}$

Received 29 June 2007; revised 29 August 2007; accepted 8 October 2007; (MWs, e.g., salinification of $\sim 0.01 /$ decade) have been imputed to local environmental changes, hence assuming unchanged inflowing Atlantic water (AW), which is an unchecked hypothesis. To better understand the long-term changes in the sea, an autonomous CTD has been moored, among others, on the Moroccan shelf in the strait of Gibraltar. We show that the inflowing AW salinity displays a marked seasonal variability, due to mixing conditions, and a huge interannual variability, having continuously increased by $\sim 0.05$ /year in 2003-2007; the AW yearly trend is dozens times larger than the MWs decadal one. The $\sim 0.20$ overall salinification being associated with a $\sim 0.12 \mathrm{~kg} / \mathrm{m}^{3}$ densification, reliable data analyses and numerical models dealing with the sea functioning must definitely consider the interannual variability of the inflow. Autonomous CTDs are efficient instruments and the variance criterion is a valuable data selection technique. Citation: Millot, C. (2007), Interannual salinification of the Mediterranean inflow, Geophys. Res. Lett., 34, LXXXXX, doi:10.1029/2007GL031179.

\section{Introduction}

[2] At seas and oceans scales, the potential temperature $(\theta)$ and salinity $(S)$ variability is generally inferred from the statistical analysis of historical ship-based data sets (bottle samplings, CTD and XBT profiles, underway surface records). Local averages (few-degree "lat-lon" space scale, monthly time scale) over years give mean seasonal signals, and linear regressions give decadal (/dec) trends (all trends thereafter are $>0$ ). The $S$ trend in the upper Atlantic across $24^{\circ} \mathrm{N}$ [Curry et al., 2003], as near $20-40^{\circ} \mathrm{N}$ [Boyer et al., $2005]$, is $\sim 0.02 /$ dec. Surface $S$ trends in the northeastern Atlantic in the $1980 \mathrm{~s}-1990 \mathrm{~s}$ reach $0.04 / \mathrm{dec}$, with relatively low values $(\sim 0.01 / \mathrm{dec})$ just west of the strait of Gibraltar [Reverdin et al., 2007]. There, the 0-200-m layer of Atlantic water (AW) likely to flow into the Mediterranean Sea is characterized by $S \sim 36.0-36.5, \theta \sim 13.5-20^{\circ} \mathrm{C}$ and potential density $\sigma \sim 26.5-27.0 \mathrm{~kg} / \mathrm{m}^{3}$.

[3] In the sea, trends $\left(\sim 0.03^{\circ} \mathrm{C} / \mathrm{dec}, \sim 0.01 / \mathrm{dec}\right)$ of some typical Mediterranean waters (MWs) were hypothetically attributed either to anthropogenic modifications, especially the Nile damming [Rohling and Bryden, 1992], or to local climatic changes [Béthoux et al., 1990]. Considering mainly the much larger warming $\left(\sim 0.3^{\circ} \mathrm{C} / \mathrm{dec}\right)$ of AW off Spain [Pascual et al., 1995], Millot [1999] emphasized that this could hardly be due to processes having occurred in the eastern basin only. Both former hypotheses implicitly assuming that AW has had stable characteristics over decades,

\footnotetext{
${ }^{1}$ Laboratoire d'Océanographie et de Biogéochimie, Antenne LOBCOM-CNRS, La Seyne-sur-mer, France.
}

Copyright 2007 by the American Geophysical Union. 0094-8276/07/2007GL031179\$05.00 which had never been verified, Millot and Briand [2002] 54 hypothesized that the sea could just be a place convenient for 55 evidencing trends occurring in the upper nearby Atlantic. $\quad 56$ [4] Even though decadal /inear trends of hydrological 57 parameters generally represent only a few $\%$ of the total 58 variance, they must be specified and understood since they 59 are of major importance at human ( decadal) scale and they 60 evidence longer ( $\sim$ secular) scales. Now, links exist between 61 hydrological parameters and societally relevant interannual 62 climatic signals such as NAO for both the Atlantic [e.g., 63 Reverdin et al., 2007] and the sea [e.g., Rixen et al., 2005], 64 and most of the variance occurs at seasonal and lower 65 (meso) scales. To correctly resolve such relatively short 66 time scales, ship-based instruments can nowadays be effi- 67 ciently complemented by arrays of moored CTDs [e.g., 68 Delcroix et al., 2005].

[5]' In the sea, time series from moored CTDs have 70 already provided valuable information [Fuda et al., 2002]. 71 There, to specify the "long-term changes", i.e. changes that 72 are not seasonal and have months-to-years scales [Millot and 73 Briand, 2002], such time series are expected to provide 74 descriptions and computations, such as correlations between 75 different places, that will allow in fine a better understanding 76 of the processes. The CIESM Hydro-Changes program was 77 then elaborated (http://www.ciesm.org/marine/programs/ 78 hydrochanges.htm) with the leading idea to maintain CTDs 79 in key-places (passages, zones of MWs formation), on short 80 $(\sim 10 \mathrm{~m})$ easily manageable sub-surface moorings for $1-81$ 2 years (yr) before servicing; CTDs being just a few meters 82 above the bottom, their nominal depth is the bottom depth. 83 Among others [Fuda et al., 2007], two CTDs operated since 84 Jan. 2003 in the strait of Gibraltar (Figure 1) to monitor the 85 in- and out-flows to and from the sea were serviced in Apr. 86 2004, Nov. 2005 (CTDs replacement) and Mar. 2007. One 87 CTD, set at $\sim 270 \mathrm{~m}$ at Camarinal Sill South, has allowed 88 showing that the outflowing MWs have been temporarily 89 warming and salting since the mid 1990s, being in the early 90 2000 s much warmer $\left(\sim 0.3^{\circ} \mathrm{C}\right)$ and saltier $(\sim 0.06)$ than 91 $\sim 20$ yr ago, a probable consequence of the Eastern Medi- 92 terranean Transient [Millot et al., 2006]. The other CTD, set 93 at $\sim 80 \mathrm{~m}$ on the Moroccan shelf to monitor the inflowing 94 $\mathrm{AW}$, allows in fact monitoring both the inflow and part of the 95 outflow; major results for the inflow are presented hereafter. 96

\section{Data Analysis}

[6] The CTDs (Sea-Bird SBE37-SMs) have sensors 98 flushed before sampling mainly to prevent sedimentation 99 on the conductivity cell. Convenient nominal accuracies 100 $\left(0.002^{\circ} \mathrm{C}, 0.0003 \mathrm{~S} / \mathrm{m}\right)$, resolution $\left(0.0001{ }^{\circ} \mathrm{C}, 0.00001 \mathrm{~S} / \mathrm{m}\right) 101$ and stability $\left(0.0024^{\circ} \mathrm{C} / \mathrm{yr}, 0.0036 \mathrm{~S} / \mathrm{m} / \mathrm{yr}\right)$, and a several- 102 year autonomy (1-h sampling) make the deployment dura- 103 tion limited mainly by the mooring resistance. Calibrations 104 made by the manufacturer before Jan. 2003 and after Nov. 105 


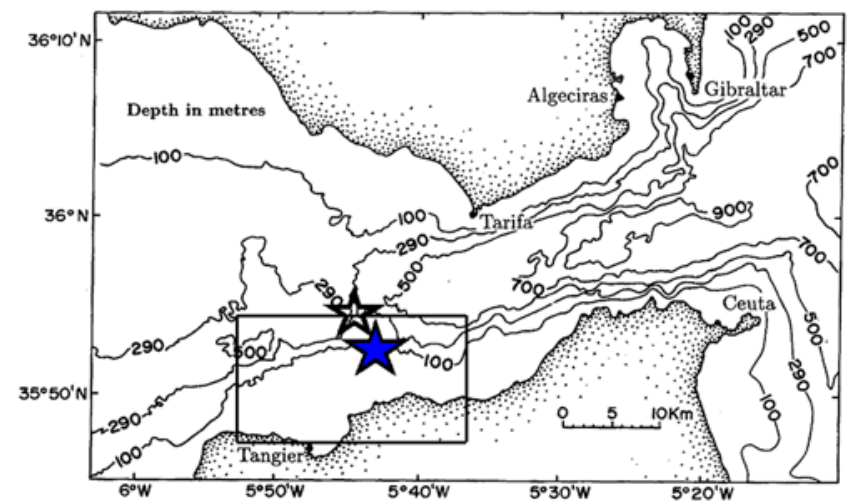

Figure 1. The study area. The blue star locates the $80-\mathrm{m}$ mooring site $\left(35^{\circ} 52.8^{\prime} \mathrm{N}-5^{\circ} 43.5^{\prime} \mathrm{W}\right)$, and the empty star locates the 270-m one. The CTD profiles in Figure 2 were acquired in the rectangular zone $\left(35^{\circ} 55^{\prime} \mathrm{N}-35^{\circ} 47^{\prime} \mathrm{N}-\right.$ $5^{\circ} 53^{\prime} \mathrm{W}-5^{\circ} 37^{\prime} \mathrm{W}$ ), mainly north of the site but also as far south as $\sim 35^{\circ} 50^{\prime} \mathrm{N}$.

2005 lead to drifts $\left(+0.000065^{\circ} \mathrm{C} / \mathrm{yr},-0.00036 \mathrm{~S} / \mathrm{m} / \mathrm{yr}\right)$ much lower than the nominal values (sensors are relatively good); assuming a linear drift during this 33-month period leads to increase the last $S$ values by 0.008 . Thanks to the short mooring length, the GPS accuracy and the shallow and smooth depth, positions/immersions are easily maintained. The data set is thus very reliable.

[7] Almost no ship-based CTD profiles are available to illustrate the stratification on the shelf near the mooring site. In the vicinity, most of the 275 profiles in the MEDATLAS database [MEDAR Group, 2002] were collected during experiments "Lynch-702-86" (70 profiles, Nov. 1985), "GIB1" (106 profiles, early Apr. 1986) and "GIB2" (90 profiles, Sep. 1986; information similar to "Lynch-70286"). The GIB1 and GIB2 S-profiles (Figure S1) show AW and the MWs in the ranges 35.8-36.4 and 38.3-38.4, resp., with the AW-MWs interface at $20-200 \mathrm{~m} .{ }^{1}$ In stratified conditions (GIB2), S(AW) increases from 35.8-36.0 at the layer base to $36.2-36.4$ at the surface, and wintertime mixing (GIB1) reduces the $S(\mathrm{AW}$ ) range to $36.10-36.35$. Both $\theta$ and $\sigma$ profiles (Figures $\mathrm{S} 2(\theta)$ and $\mathrm{S} 3(\sigma)$ ) are monotonous and more seasonally variable, but all 3 parameters are potentially efficient to separate AW $\left(\mathrm{S}<37, \theta>13.5^{\circ} \mathrm{C}, \sigma<28 \mathrm{~kg} / \mathrm{m}^{3}\right)$ from the MWs $\left(\mathrm{S}>38, \theta<13.25^{\circ} \mathrm{C}, \sigma>29 \mathrm{~kg} / \mathrm{m}^{3}\right)$. Classically, early spring is more favorable than fall to sample "pure" AW, i.e. to get data representative of an unstratified and unmixed (with the MWs) AW.

[8] The GIB1,2 profiles having been collected within relatively short periods, the $20-200-\mathrm{m}$ displacement of the AW-MWs interface is mainly due to the huge internal tide, so that AW and the MWs can be measured at $\sim 80 \mathrm{~m}$, most often at different levels within each layer thanks to the tide. The time-series in Figure 2 show that, except during neaps (near $\mathrm{d} \# 13$ ) when the tide is mainly diurnal, the CTD clearly samples successively, on a semi-diurnal basis, AW $(S \sim 36.0-36.5)$ and the MWs $(S \sim 38.4-38.5$; note the $\sim 0.1$ increase from the GIB1,2 data [Millot et al., 2006]). However, data representative of relatively pure AW (or MWs) have to be selected.

${ }^{1}$ Auxiliary materials are available in the HTML. doi:10.1029/ 2007GL031179.

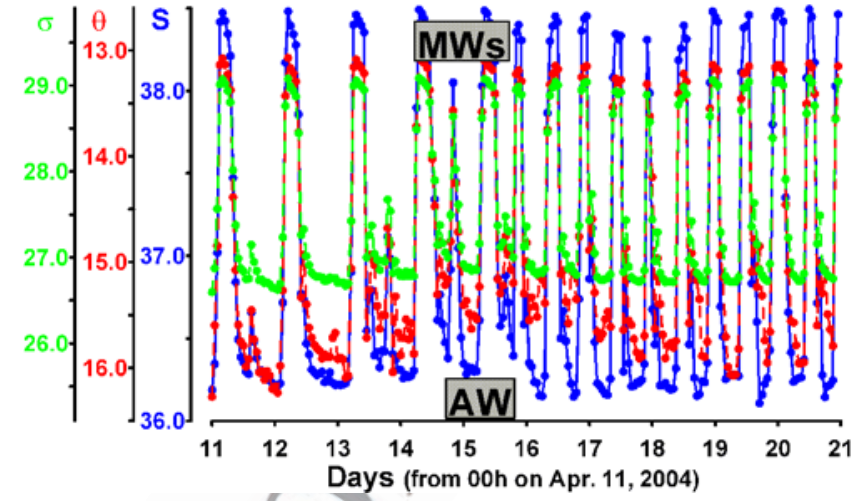

Figure 2. The 10 days of the 1 -h $S$ (blue), $\theta$ (red), and $\sigma$ (green) time series.

[9] A simple "limit criterion" (e.g., $S<36.9$ ) selects 145 $\sim 24000$ (out of 36600) data (Figure 3). This non-objective 146 criterion does not eliminate data indicative of mixing with 147 the MWs, cannot provide any representative mean and gives 148 a biased selection with long-term changes. Nevertheless, the 149 lowest $S$ data document the seasonal variability expected 150 from the GIB1,2 data set and display a 50-month overall 151 increase (trend $\sim 0.033 / \mathrm{yr}$, coefficient of determination 152 $\left.r^{2}-0.04\right)$

153

[10] A more objective "tidal criterion" that considers the 154 lowest $S$ value during each semi-diurnal $(12 \mathrm{~h}$ ) cycle selects 155 3050 data. It does not have the limit criterion's defaults and 156 gives a more reliable trend $\left(\sim 0.046 / \mathrm{yr}, r^{2} \sim 0.22\right)$. However, 157 no information is provided about the significance of a 158

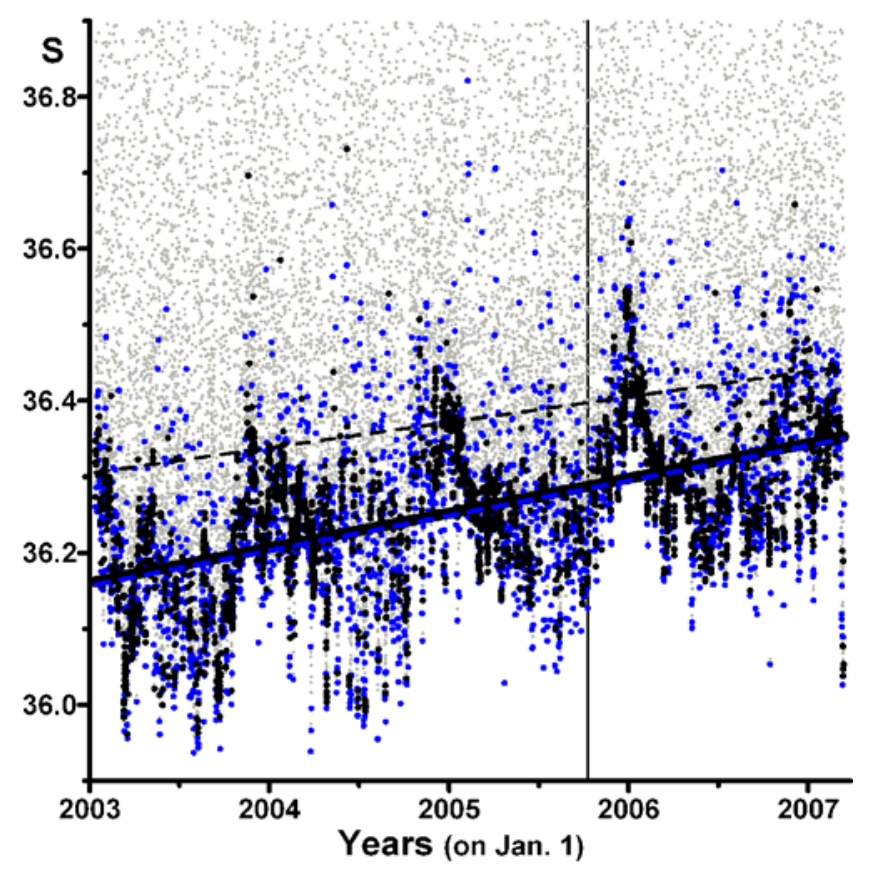

Figure 3. The $S(\mathrm{AW})$ selection. $S$ data selected with the limit criterion (grey dots; trend: black dashed line), the tidal criterion (blue dots; trend: blue dashed line), and the variance criterion (black dots; trend: black solid line); see text for details. The vertical line specifies the CTD replacement. 


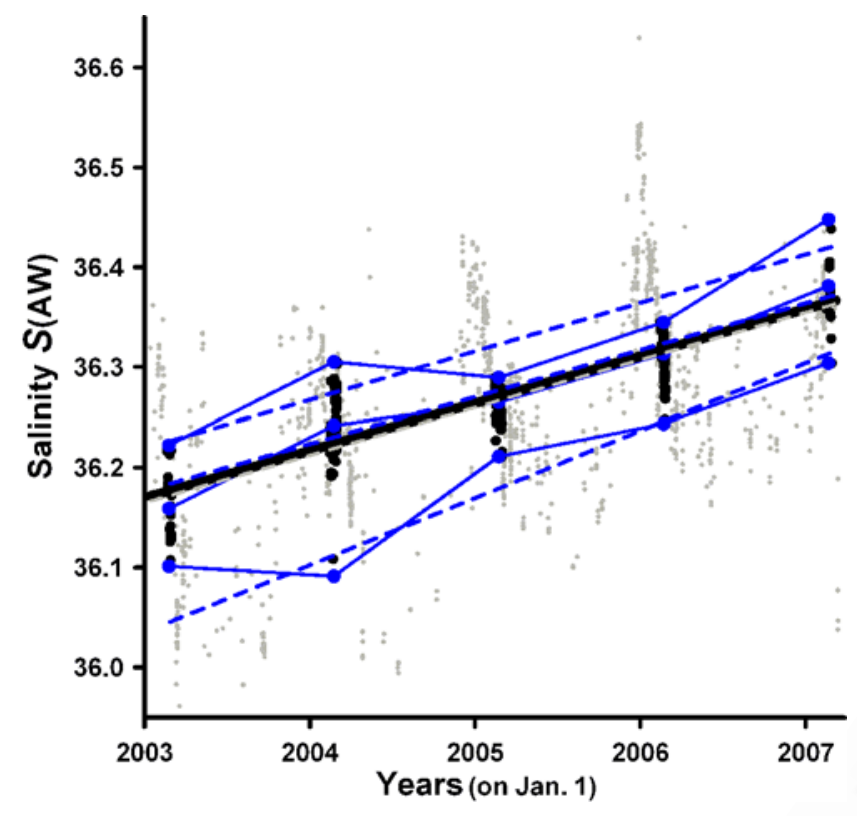

Figure 4. Distribution of the $S(\mathrm{AW})$ data. The 1444 triplets (grey dots; trend: grey dashed line), the 274 triplets during the 5 most favourable Feb. periods (black dots; trend: black solid line), and the minimum $S_{\text {min }}$, mean $S_{\text {mean }}$, and maximum $S_{\max }$ values during each of these periods plotted in the middle of the periods (blue dots connected by solid blue lines; trends: blue dashed lines). selected data, i.e. whether it represents pure AW, or stratified AW or AW more or less mixed with the MWs. Selecting the "minimum-minimorum" over some given period could provide information on the $S$ minimum value at the AW layer base but, to be reliable, such a representation of pure AW would need a continuous $S$ record (note that all values we measured are $>35.9$ while values $<35.9$ were measured during GIB2). Also, no information is provided by the tidal criterion about the number of similar data measured during the tidal cycle, which is important since a data representative of a given water must be measured "quite a while".

[11] A selection as objective and informative as possible is made with a "variance criterion" that selects only the data for which the standard deviation (sd), computed with the data before and the data after, is lower than an arbitrary chosen limit that quantifies "homogenization"; data selected in such a way can represent either pure water or water well mixed with others. Choosing a limit larger or lower allows selecting more or less data representative of more or less homogeneous water at one's convenience, but still in a fully objective manner (more arguments and details about the variance technique are given by $\mathrm{C}$. Millot (manuscript in preparation, 2007a)). The same amount of $3050 \mathrm{~S}$ data is selected with a sd limit $=0.011399$. Even though isolated $S$ minima selected with the tidal criterion, which are actually representative of AW unmixed with the MWs, are missed with the variance criterion, data are distributed over similar ranges and lead to a similar trend $\left(\sim 0.046 / \mathrm{yr}, r^{2} \sim 0.29\right)$. To select a data set even more representative of homogeneous AW, not only $S$ but also $\theta$ and $\sigma$ should be considered similarly since all parameters are potentially efficient. To be consistent with the selection from the more-classical tidal 191 criterion, $3050 S, \theta$ and $\sigma$ data were selected with specific sd 192 limits (0.011399 in $S, 0.051456$ in $\theta, 0.013510$ in $\sigma$ ). Data 193 for each parameter being selected at possibly different 194 times, simultaneous data form triplets (1444) that sharpen 195 the selection and, being selected in a fully objective manner, 196 form the best set of data representative of relatively homo- 197 geneous AW. The trend associated with these $1444 S$ data is 198 $\sim 0.047 /$ yr $\left(r^{2} \sim 0.30\right.$, Figure 4).

\section{Discussion}

\subsection{Salinification at $80 \mathrm{~m}$}

[12] Even though the sd-selected data spread over a 202 relatively wide range and can be encountered all year long, 203 they display a marked seasonal variability (maximum in 204 winter, minimum in summer, amplitude $\sim 0.4$ ). Homoge- 205 neous AW is more easily observed in late winter-early 206 spring (Figures 4 and S4): at this time and place, the AW 207 layer is i) not seasonally stratified yet and ii) no more mixed 208 with the MWs as during the winter; the sd-selected data set 209 in early spring-late winter thus provides the most reliable 210 representation of pure AW salinity and is noted $S(\mathrm{AW})$. On 211 average, data/triplets are relatively numerous in late Feb. 212 (Figure S4) so that considering the sole 15-day periods 213 starting on Feb. 15 leads to 24, 59, 105, 70 and 16 triplets 214 (274 in total) for 2003-2007 and a trend of $0.047 / \mathrm{yr} 215$ $\left(r^{2} \sim 0.72\right)$. The mean values for each period $\left(S_{\text {mean }}\right)$ are 216 $36.159,36.242,36.265,36.313$ and 36.381 , their trend is 217 still $0.047 / \mathrm{yr}\left(r^{2} \sim 0.96\right)$ and the 2003-2007 $S_{\text {mean }}$ increase 218 is $\sim 0.22 ; S_{\min }$ and $S_{\max }$ trends are similar $(\sim 0.067 / \mathrm{yr}$ and 219 $\sim 0.048 /$ yr).

220

[13] Whatever the criterion, period, parameter and statis- 221 tical variable used to objectively identify pure AW, the 222 lowest $S$ values have increased, in 2003-2007, by $\sim 0.047 /$ yr, 223 hence by $\sim 0.188$; this almost regular/linear increase 224 might have to be considered also (even if possibly lower) 225 during the previous and forthcoming years. All trends being 226 clearly significant (t-test), we retain nominal values of 227 $\sim 0.05 / \mathrm{yr}$ and $\sim 0.20$ for $2003-2007$. If necessary, the 228 $S(\mathrm{AW})$ trend is validated by the $S(\mathrm{MWs})$ data that are 229 spread over a lower range and do not display any significant 230 trend (not shown). Now, how representative of the whole 231 AW layer the $80-\mathrm{m}$ time series is?

$$
232
$$

\subsection{AW Layer}

[14] It is known that $S$ variations are forced mainly at the 234 surface so that a $S$ increase in the upper AW layer leads to a 235 $\sigma$ increase, hence to a de-stratification of the layer (and vice 236 versa). As compared to the $S$ data, the $\theta$ and $\sigma$ ones (Figures 237 S5 $(\theta)$ and S6 $(\sigma))$ a more interannually variable, AW 238 having been relatively warm and light in 2004 and 2007; 239 $\theta$ does not display any significant trend while $\sigma$ increases by 240 $\sim 0.118 \mathrm{~kg} / \mathrm{m}^{3}$ in $2003-2007$ (nominal value $\sim 0.12 \mathrm{~kg} / \mathrm{m}^{3}$ ). 241 A $\sim 0.188$ salinification (with $\theta \sim 15.5^{\circ} \mathrm{C}$ at $80 \mathrm{~m}$ ) leading to 242 a $\sim 0.145 \mathrm{~kg} / \mathrm{m}^{3}$ densification, the $\sigma$ interannual trend 243 mainly results from the $S$ one.

[15] The $S_{\min }(36.101,36.091,36.211,36.244,36.304) 245$ and $S_{\max }(36.222,36.305,36.290,36.345,36.448)$ for the 5246 15-day Feb. periods being consistent with the expected 247 ranges, most of the values representative of the AW layer 248 were probably sampled. The interface oscillating at 20-200 m 249 (Figures S1, S2, and S3), i.e. near the 80-m sampling depth, 250 
the lowest values at the layer base necessarily correspond to $S_{\min }$. The upper AW layer non-stratification during such periods suggests that the highest values correspond to $S_{\max }$; but even larger actual maxima necessarily encounter a trend similar to the $S_{\max }$ one (if not, the upper layer would be stratified in winter). The 2003-2007 $S_{\min }$ trend cannot result from the sole mixing/de-stratification of the AW layer (the $S_{\max }$ trend would be $<0$ ), as due for instance to waves amplitude increasing over years. Therefore, the $S_{\min }, S_{\text {mean }}$ and $S_{\max }$ trends account for a 2003-2007 salinification of the whole AW layer in the study area.

[16] The mooring site is in the central-southern part of the strait, relatively far from the Moroccan coast. AW being more frequent than MWs during neaps (e.g., Figure 2), $80 \mathrm{~m}$ is above the mean level of the AW-MWs interface there. Furthermore this interface is sloping down southward so that most AW is found in the southern part of the strait, a 4-year regular trend cannot be specific to the study area and is representative of the whole Mediterranean inflow, hence to the surface water in the nearby Atlantic.

\subsection{Consequences for the Sea and the Ocean}

[17] Even though this is not a result of our own data analysis, it must first be emphasized that the $S$ decadal trends now available for AW likely to enter the sea [e.g, Reverdin et al., 2007] are similar $(\sim 0.01 / \mathrm{dec})$ to those for the MWs within the sea. Because MWs are nothing else than AW transformed by the E-P forcing, decadal trends similar for AW and the MWs account for no major changes in the transformation (contrary to what is usually thought). This supports the former hypothesis [Millot and Briand, 2002] that the sea could just be a place convenient for evidencing trends occurring at a much larger scale, Consequently, environmental/transformation changes within the sea could have had an importance in global change much lower than previously thought [e.g., Johnson, 1997].

[18] To be noticed is that $\theta$ decadal trends of AW and the MWs in the sea can result from a $S$ (in fact $\sigma$ ) decadal trend of AW entering the sea since less wintertime cooling is then needed for AW to reach the critical density that will lead it to sink and be transformed into the MWs. Accurate computations can hardly be made since the AW decadal trends (inferred from relatively few underway surface records) are less significant than the MWs ones (inferred from numerous CTDs profiles, at least for the deep water of the western basin).

[19] Whatever the relationships between the decadal trends in and out of the sea, can the clear $S(\mathrm{MWs})$ decadal trend (over $\sim 4 \mathrm{dec}$ ) be related to the clear $S(\mathrm{AW}$ ) interannual trend (over $\sim 4 \mathrm{yr}$ ) that is dozen times greater? The interannual trend cannot be extrapolated to the former decades since $S(\mathrm{AW})$ values in 2003 are close to those in the mid 1980s and before. It might reveal a recent (last years only since no similar interannual trend has been observed yet for the MWs) unique dramatic change in the nearby Atlantic, but we are not aware of any relevant information. It might also reveal a huge permanent interannual $S(\mathrm{AW})$ variability, the 2003-2007 salinification hence having to be somehow compensated by an equivalent (past or forthcoming) freshening in order to match the decadal trends.

[20] The interannual variability being hardly specified with the sole ship-based opportunistic data sets available up to now in both the sea and the ocean, we think it has 312 been largely underestimated and must imperatively be 313 correctly resolved. Additionally, it seems hardly conceiv- 314 able that reliable data analyses and numerical models 315 dealing with the functioning of the sea and considering 316 the interannual variability of the forcings could avoid taking 317 into account the interannual variability of the inflow char- 318 acteristics $(\sim 0.2$ over $4 \mathrm{yr})$, and its seasonal variability 319 (amplitude $\sim 0.4$ ) as well.

[21] Densification of the AW layer has consequences for 321 the outflow since both strongly mix within the strait [e.g., 322 Bryden et al., 1994]. In addition, contrary to what is 323 generally assumed, all major MWs can be recognized in 324 the outflow and they are less vertically superposed than 325 horizontally juxtaposed, all of them hence mixing with AW 326 (C. Millot, manuscript in preparation, 2007b). Interannual 327 modifications of the inflow thus directly lead to interannual 328 modifications of the whole outflow that should be sensed at 329 the 1000-1200-m Mediterranean level in the Atlantic.

\section{Conclusion}

330

[22] Thanks to the internal tide and to the specific 333 conditions in the strait of Gibraltar, a unique CTD moored 334 at $80 \mathrm{~m}$ on the Moroccan shelf allows monitoring correctly 335 the hydrological characteristics of both the inflowing AW 336 and the MWs outflowing there.

[23] In 2003-2007, the AW has encountered a huge 338 salinification $(\sim 0.05 / \mathrm{yr}$, i.e. $\sim 0.2)$ together with mainly con- 339 sequent densification $\left(\sim 0.03 \mathrm{~kg} / \mathrm{m}^{3} / \mathrm{yr}\right.$, i.e. $\left.\sim 0.12 \mathrm{~kg} / \mathrm{m}^{3}\right) .340$ Such an interannual trend cannot be extrapolated to 341 decades but shows how large the interannual variability of 342 the inflow characteristics can be. In addition, AW decadal 343 trend values now available for the nearby ocean being 344 similar to those of the MWs, former hypotheses about the 345 latter only involving changes in the sea as well as their 346 possible consequences at global scale are weakened; the 347 Mediterranean Sea could just be a place convenient for 348 evidencing changes occurring at the surface in the nearby 349 Atlantic.

[24] For the sea, not only studies about hydrological 351 trends but also studies about dense water formation and 352 circulation, which take into account the interannual vari- 353 ability of the forcings, must take into account the interan- 354 nual variability of the inflow. Due to mixing in the strait, 355 direct consequences for the outflow and the global ocean 356 cannot be ignored too.

[25] Finally, this analysis, together with previous and on- 358 hand ones, account for the reliability of autonomous CTDs 359 and for their efficiency to monitor long-term changes in 360 specific locations. A variance criterion appears to be an 361 efficient and fully objective technique to select data repre- 362 sentative of homogeneous water, pure water being then 363 differentiated from water well mixed with others according 364 to scientific knowledge in the study area.

[26] Acknowledgments. I thank i) Frédéric Briand, general director 366 of CIESM (Commission Internationale pour l'Exploration Scientifique de 367 la mer Méditerranée), for his consequent and permanent support, ii) 368 Youssef Tber for his enthusiasm in initiating the monitoring there, iii) 369 the SHOMAR (Service Hydrographique et Océanographique de la Marine 370 Royale du Maroc) for its efficient logistics, iv) Jean-Luc Fuda and Gilles 371 Rougier for their help during the servicing, and v) both reviewers. This is 372 
a contribution to the Hydro-Changes CIESM program (http://www.ciesm. org/marine/programs/hydrochanges.htm).

\section{References}

Béthoux, J. P., B. Gentili, J. Raunet, and D. Tailliez (1990), Warming trend in the western Mediterranean deep water, Nature, 347, 660-662.

Boyer, T. P., S. Levitus, J. I. Antonov, R. A. Locarnini, and H. E. Garcia (2005), Linear trends in salinity for the World Ocean, 1955-1998, Geophys. Res. Lett., 32, LO1604, doi:10.1029/2004GL021791.

Bryden, H. L., J. Candela, and T. H. Kinder (1994), Exchange through the Strait of Gibraltar, Prog. Oceanogr., 33, 201-248.

Curry, R., B. Dickson, and I. Yashayaev (2003), A change in the freshwater balance of the Atlantic Ocean over the past four decades, Nature, 426, $826-829$

Delcroix, T., M. J. McPhaden, A. Dessief, and Y. Gouriou (2005), Time and space scales for sea surface salinity in the tropical oceans, Deep Sea Res., Part I, 52, 787-813.

Fuda, J. L., G. Etiope, C. Millot, P. Favali, M. Calcara, G. Smriglio, and E. Bo (2002), Warming, salting, and origin of the Tyrrhenian Deep Water, Geophys. Res. Lett., 29, 1886, doi:10.1029/2001GL014072.

Fuda, J.-L., et al. (2007), Hydro-Changes: First results and perspectives, Rapp. P. Reun. Comm. Int. Explor. Sci. Mer Mediterr., 38, 27.

Johnson, R. G. (1997), Climate control requires a dam at the Strait of Gibraltar, Eos Trans. $A G U, 78,227-281$.

MEDAR Group (2002), MEDATLAS/2002 Database: Mediterranean and Black Sea Database of Temperature Salinity and Bio-chemical Para-
meters-Climatological Atlas [CD-ROM], Inst. Fr. de Rech. Pour 1'Ex- 398 ploit. de la Mer, Brest, France. 399

Millot, C. (1999), Circulation in the western Mediterranean sea, J. Mar. 400 Syst., 20, 423-442.

Millot, C. and F. Briand (2002), Executive summary, in Tracking Long Term 402 Hydrological Change in the Mediterranean Sea, edited by F. Briand, 403 CIESM Workshop Ser., 16, 7-14.

Millot, C., J. Candela, J.-L. Fuda, and Y. Tber (2006), Large warming and 405 salinification of the Mediterranean outflow due to changes in its compo- 406 sition, Deep Sea Res., Part I, 53, 656-666.

Pascual, J., J. Salat, and M. Palau (1995), Evolucion de la temperatura del 408 mar entre 1973 y 1994, cerca la coasta catalana, Actes Coll. Sci. OKEANOS, 409 95, 23-28.

Reverdin, G., E. Kestenare, C. Frankignoul, and T. Delcroix (2007), Sur- 411 face salinity in the Atlantic Ocean $\left(30^{\circ} \mathrm{S}-50^{\circ} \mathrm{N}\right)$, Prog. Oceanogr., 73, 412 $311-340$.

Rixen, M., et al. (2005), The Western Mediterranean Deep Water: A proxy 414 for climate change, Geophys. Res. Lett., 32, L12608, doi:10.1029/ 415 2005GL022702.

Rohling, E. J., and H. Bryden (1992), Man-induced salinity and tempera- 417 ture increases in Mediterranean deep water, J. Geophys. Res., 97, 418 $11,191-11,981$

C. Millot, Laboratoire d'Océanographie et de Biogéochimie, Antenne 421 LOB-COM-CNRS, BP 330, F-83507 La Seyne-sur-mer, France. (cmillot@, 422 ifremer.fr)

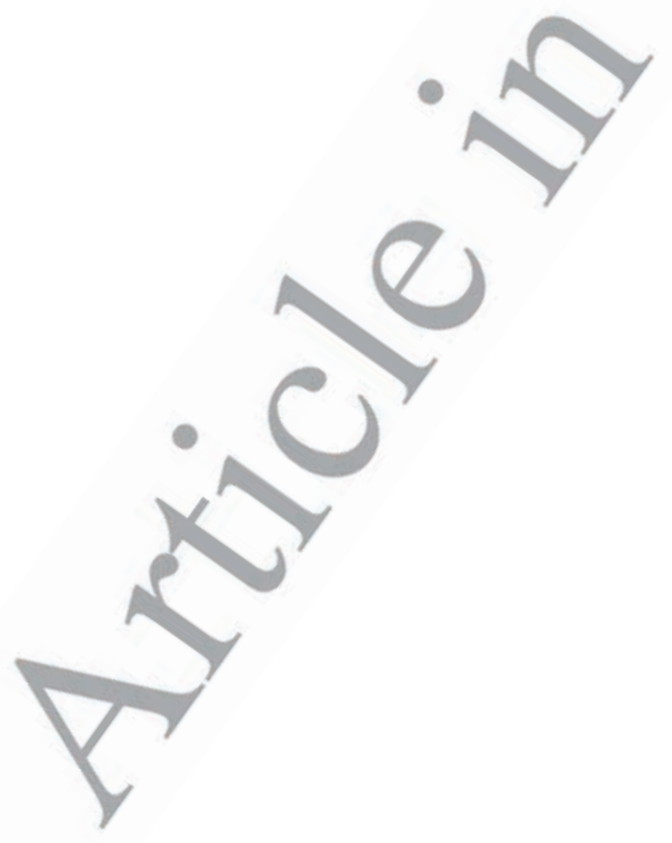

